\title{
Espacios liminares: metamorfosis monstruosas de la casa en textos de Daína Chaviano y Mariana Enríquez
}

\section{Liminal spaces: monstrous metamorphoses of the house in Daína Chaviano and Mariana Enríquez's texts}

\author{
Rosa María Díez Cobo \\ Universidad de Burgos, Grupo GEIG, España \\ rmdiez@ubu.es \\ iD https://orcid.org/0000-0001-7932-5315
}

Fecha de recepción: 02/03/2021

Fecha de aceptación: 30/03/2021

\section{Resumen}

El motivo de la casa encantada ha ganado gran visibilidad en los últimos tiempos en las literaturas de lo insólito en español. Concebida esta no solo como lugar anómalo, sino también como criatura fantástica, sus potenciales idiosincrasias arquitectónicas recrean en algunos textos territorios mutantes con notable impulso crítico y simbólico. Tomando como referencia las teorizaciones sobre el espacio fantástico y, en concreto, las enfocadas a sus fronteras y límites, en este trabajo se analizarán dos narrativas particularmente representativas: Casa de juegos (1999) de la cubana Daína Chaviano y Nuestra parte de noche (2019) de la argentina Mariana Enríquez. Este ejercicio comparativo pretende desvelar las similares estrategias de ambas autoras a la hora de forzar a sus protagonistas a penetrar en zonas heterotópicas, con sus propias normas y rituales. En los dos textos, además, verificaremos cómo sus casas protagonistas se conforman como trasunto de fenómenos históricos y sociales traumáticos y convulsos.

Palabras clave: casas monstruosas; espacios liminares; metamorfosis arquitectónicas; reescrituras históricas; Daína Chaviano; Mariana Enríquez. 


\begin{abstract}
Lately, the haunted house motif has gained great visibility in the literatures of the fantastic in Spanish. Conceived not just as an anomalous space, but also as a fantastic creature, its potential architectural idiosyncrasies recreate, in some texts, mutant territories endowed with a considerable critical and symbolic momentum. This essay will analyse two particularly representative narratives, Casa de juegos (1999) by Cuban Daína Chaviano and Nuestra parte de noche (2019) by Argentinean Mariana Enríquez, taking as a reference theories on the fantastic space and, most particularly, those focused on its frontiers and limits. This comparative exercise aims to reveal both authors' similar strategies when forcing their protagonists to penetrate into heterotopic spaces, with its own norms and rituals. Additionally, in the two texts we will verify how their principal houses are shaped as a projection of traumatic and tumultuous historical and social events.
\end{abstract}

Keywords: monstrous houses; liminal spaces; architectural metamorphoses; historical rewritings; Daína Chaviano; Mariana Enríquez.

Financiación: Esta publicación es parte del proyecto de I+D+i PGC2018-093648-B-I00, financiado por MCIN/ AEI /10.13039/501100011033/ FEDER «Una manera de hacer Europa» - Estrategias y figuraciones de lo insólito. Manifestaciones del monstruo en la narrativa en lengua española (de 1980 a la actualidad).

\title{
Reflexiones preliminares: sobre las casas fantásticas y sus fronteras
}

En el ámbito de la literatura fantástica, comprendida esta en los términos establecidos por David Roas (30-35) como una incursión alarmante y desestabilizadora de lo imposible en los territorios de lo real, el dominio de la casa encantada, embrujada o maldita resulta siempre un tópico fértil y recurrente. Pero, si esto parece ser una asunción común, en menor grado se concibe lo arquitectónico como asimilable a lo monstruoso. Aunque, justamente, en esa dirección, apunta Noël Carroll en The philosophy of horror: or, paradoxes of the heart cuando lista a las casas encantadas dentro de su rúbrica de «monstruos por fusión» (45). Es decir, según este autor, una casa de esta condición anómala amalgama aspectos ontológicamente dicotómicos, excluyentes, que le otorgan una naturaleza indudablemente terrorífica o inquietante. Entre dichos elementos antagónicos, el más común en muchas narrativas insólitas es la superposición de la naturaleza inorgánica e inerte que le correspondería como objeto y la posibilidad vital que le otorga su naturaleza embrujada. Es decir, la construcción encantada, además de ser continente de sucesos o seres escalofriantes, en ocasiones, y más visiblemente en la literatura posmoderna, aparece dotada de posibilidades metamórficas y volitivas que desafían cualquier concepción del espacio y de la arquitectura dentro de un orden real o realista.

Todos estos particulares los ha estudiado profusamente la investigadora Patricia García en su trabajo pionero Space and the posmodern fantastic in contemporary literature (2015). En concreto, esta autora, en el marco del «giro espacial» de las ciencias 
y las humanidades a lo largo del siglo xx, realiza una minuciosa distinción entre los modelos contrapuestos fantastic of place y fantastic of space -lo fantástico de lugar versus lo fantástico del espacio. El segundo de estos modelos se corresponde con una consideración de lo espacial como un motor o agente primario de la transgresión fantástica, como un cuestionador de las leyes del espacio, y no como mero receptáculo o escenario, como sería el caso de lo fantástico de lugar (21). Entroncando con esta misma línea de pensamiento, es el propósito de este estudio llamar la atención hacia dos novelas hispanoamericanas contemporáneas que exploran esta vía de la casa encantada cristalizada como ser agencial y mutante y origen de una panoplia de distorsiones siniestras de la realidad. Se trata, por un lado, de la novela Casa de juegos (1999) de la narradora cubana Daína Chaviano y, por otro, de la última creación de la autora argentina Mariana Enríquez, Nuestra parte de noche (2019), obra ganadora del prestigioso premio Herralde de novela.

Ambas escritoras, dos de las representantes más sobresalientes de la literatura insólita en la literatura latinoamericana, comparten, además, un interés reiterado por yuxtaponer ficción e historia, lo que resulta, en estos textos, en un territorio discursivo crítico particularmente fructífero. En el caso de Casa de juegos, de la mano de su joven protagonista, la estudiante universitaria Gaia, nos adentramos en una Habana oculta, en una dimensión paralela donde habitan los orishas de la tradición santera de origen yoruba pero, y de ahí resulta lo insólito de este relato, que intersecciona constantemente con el plano de lo real y lo histórico ${ }^{1}$. Gaia, en una suerte de ordalía sexual vivida de la mano de estos seres del panteón mítico afro-cubano, emprende una exploración de su identidad y, en conjunto, de la del pueblo cubano, durante los años 90 del siglo $\mathrm{xx}$, bajo las atosigantes condiciones económicas y sociales del «Periodo especial en tiempos de paz» en la isla caribeña. Por su parte, Nuestra parte de noche, dibuja las peripecias de Gaspar, un joven que va creciendo sección a sección, década a década, ante nuestros ojos, y de otros miembros de su familia perteneciente a una oscura orden secreta espiritista ${ }^{2}$. Mediante procedimien-

1. Esta novela es la segunda de un ciclo de cinco obras denominada por la autora como «La Habana oculta» donde cada una de ellas abarca distintos periodos cronológicos en la historia de la isla. En todas, realidad y fantasía, esta última en una vertiente pronunciadamente espiritual, se hibridan con un mismo objetivo: mostrar senderos existenciales o catárticos alternativos para sus protagonistas con el fin de sobrevivir en contextos sociales asfixiantes (Chaviano, Daina Chaviano Author. Sitio web oficial, 2008-2021).

2. Buena parte de la obra ficcional de Mariana Enríquez hasta el momento ha orbitado en torno a la confluencia de lo terrorífico con representaciones realistas de la sociedad contemporánea, fundamentalmente argentina. En sus dos últimos volúmenes de relatos, Las cosas que perdimos en el fuego (2016) y Los peligros de fumar en la cama (2017) revisita y actualiza tópicos clásicos del gótico global (Botting y Edwards, 2013) y latinoamericano (Casanova-Vizcaíno y Ordiz, 2017), desde el ángulo local de su propio país. Pero es en el relato «La casa de Adela», en Las cosas que perdimos en el fuego, donde nos encontramos el germen, literal, de Nuestra parte de 
tos rituales sangrientos, llenos de vejámenes, dicha orden anhela comunicarse con entes siniestros para encontrar el secreto de la pervivencia eterna de la conciencia. A la peripecia personal de los protagonistas le acompańan, como rumor atronador de fondo, los desmanes perpetrados por la Junta Militar argentina entre los años 70 y 80 del siglo xx y, con el paso de los sucesivos capítulos, las diversas crisis que asolaron el país en los 90 .

Metodológicamente, hay que tener en cuenta que nos encontramos ante dos narrativas que, por su volumen y complejidad de las tramas, difieren enormemente. Casa de juegos es una novela relativamente breve, dividida en dos apartados principales y que recorren un corto espacio en la vida de Gaia. En cambio, la novela de Enríquez se acerca a las 700 páginas, agrupadas en seis capítulos, y urde un trabado y complejo entramado de historias a lo largo de cuatro décadas y donde afloran multitud de personajes. Debido a esta evidente desigualdad estructural y diegética, el presente análisis se concentra en aquellas cuestiones fundamentales tocantes al rol de las construcciones fantásticas que en ellas hacen aparición. En este sentido, ambas novelas se hallan hermanadas por multitud de convergencias conceptuales y simbólicas que se pueden abordar desde diversos frentes de lo fantástico en su proyección espacial. De todos estos elementos en común cabe destacar la recurrencia de la liminaridad como clave física y metafórica.

Limes (plural limites) es el vocablo latino para referirse al límite, al umbral, al pórtico o a la entrada, de ahí el término liminar (Neumann 473). El uso de esta noción, entendida como fase de un proceso, alcanzó su visibilidad académica en los campos de la etnografía y la antropología de las manos de Arnold van Gennep en Los ritos de paso (1909) y El proceso ritual (1969) de Victor Turner desde una perspectiva que identifica las liturgias humanas, sagradas y sociales, como tránsitos entre dos estadios, entre dos modos de ser en sociedad e identificarse. El paso del umbral, de la frontera entre el ser preliminar y el posliminar, la suspensión o arresto transitorio que ello implica (Neumann 474), cruce simbólico literalizado a través de la ceremonia ritual, ha sido empleado de forma productiva en la crítica literaria, sobre todo la que se ocupa de la literatura fantástica. En este sentido, por ejemplo, el monstruo, figura central dentro de los universos de lo fantástico, posee una naturaleza limítrofe, intersticial, inclasificable y, por lo tanto, atemorizante, tabú, como ya argumentó la antropóloga Mary Douglas en su obra Purity and danger (1966) y, como, posteriormente, ha refrendado en el campo estrictamente literario Ana Casas en su prólogo a la antología Las mil caras del monstruo (2012) 3 .

noche. En la novela se reincorpora el grueso de la historia original ampliándola, contextualizándola y resolviéndola, sin perder de vista sus conexiones con la visibilización de la desaparición de opositores durante la última dictadura militar en Argentina.

3. Andrea Castro en su artículo «El motivo del umbral y el espacio liminal» (2007) acopia un buen número de teorías que abordan la relación del tópico del umbral con el fantástico. 
La casa encantada corresponde a esta percepción de lo que no encuentra acomodo entre las codificaciones usualmente aceptadas en nuestro horizonte de expectativas de lo verosímil y, en algunos casos, nos adentra en un proceso transfigurativo entre límites categoriales. Como también señala Patricia García, los espacios liminares en la literatura fantástica posmoderna no solo trasgreden los conceptos binarios acostumbrados, sino que articulan las presencias y las ausencias, cuestión que se materializa en no pocas ocasiones mediante un procedimiento semántico catacrético donde conceptos como el de casa, o umbral, entre otros, en realidad modelan referencialmente estos espacios alternos, abominables, que no encuentran un paralelismo mensurable y tangible en nuestra realidad extratextual (43). Se trata, por lo tanto, de nociones maleables, cambiantes, en proceso de devenir otra entidad. $Y$ es que, como veremos en las edificaciones que salpican las dos novelas de Chaviano y Enríquez, carecemos de términos adecuados para definirlas, ni tan siquiera para comprenderlas completamente: ¿se trata realmente de construcciones cimentadas, de ensoñaciones surgidas de la mente de sus personajes, de bocas ávidas o de portales a otra dimensión? Si bien no podemos hallar respuesta concluyente a esta cuestión dentro de los propios textos, sí podemos encontrar una apoyatura en la centralidad que los ritos ocupan en ellos. Y es que en las dos novelas el componente fantástico se halla apuntalado por prácticas sacras y/o esotéricas que implican ceremoniales de paso de diversa índole. No en vano, en la novela de Enríquez incluso se citará explícitamente a van Gennep y Turner (430) en un ejercicio posmoderno intertextual y paródico donde se conjuga lo literario con su propia exégesis.

Desgranaremos la operatividad fantástica del limen en los dos textos desde un frente bipartito. En primer lugar, como acabamos de apuntar, en ambos casos se nos presentan personajes sumergidos en situaciones donde cultos populares o creencias sincréticas de distinto signo permean sus vivencias y siempre teniendo como epicentro una casa o casas de naturaleza insólita. Así, en la primera sección de este análisis se considerará las transiciones entre el exterior, la realidad, y el interior de estos hogares, el universo fantástico, con un particular enfoque en la relación entre la ritualidad y los umbrales. Adentrándonos junto con sus protagonistas en estas construcciones, atenderemos al trance que implica penetrar en territorios dominados por fuerzas instintivas extremas que delinean, en cada una de las novelas, escenarios enfrentados de sexualidad, dolor y muerte. En segundo término, coinciden también las dos narrativas y sus edificios en erigirse como trasuntos de procesos convulsos de las historias cubana y argentina contemporáneas comportando, así, una dimensión ulterior de lo constructivo como ente mudable y, por lo tanto, necesariamente, siniestro. Cuando la nación adopta la extensión reducida de un hogar caótico, con límites imprecisos y poblada por seres desconocidos, fronterizos o abyectos, dicho espacio multiplica y dinamita simultáneamente sus conexiones extratextuales y referenciales. En este apartado, pues, nos dedicaremos a considerar este particular proceso de prosopopeya. 


\section{Casas en las afueras: liminaridad y ritual}

En Casa de juegos, aunque vislumbramos al inicio de la novela, cual anticipos, algunos espacios en sombra de La Habana que preludian la transición de Gaia al territorio de lo insólito y mágico, una sola mansión se convierte en el vórtice que atrapa la frustración personal y la represión institucionalizada y la transforma en un torrente orgiástico de liberación y evasión. A ella llega la protagonista tras su visita a una iyalocha, una santera, en un intento por revertir la crónica inapetencia amorosa y sexual que sufre tras la muerte de un amante. La santera la inicia en el conocimiento sobre el cosmos orisha y le vaticina su encuentro con un hombre que romperá con su frigidez, es decir, por este procedimiento Gaia atraviesa un primer umbral ritual que se materializará con la aparición de un atractivo joven, Eri, que tras invitarla a un pantagruélico banquete la someterá sexualmente. Este segundo progreso la orientará, definitivamente, en la dirección de la casona protagonista. Orillada en un recodo de la ciudad que, misteriosamente, Gaia nunca logra encontrar por sí misma, ingresa en el lugar en varias ocasiones de manos de sus ambivalentes anfitriones: Eri y su supuesta hermana que, gradualmente, se revelarán como encarnaciones orishas de Erinle, deidad de las aguas y Oshún, que también preside las aguas, el amor y la fertilidad. La impresión que le produce el caserón en su primera visita es honda: «Era como llegar a un Averno sin llamas» (62). El lugar, descrito como sincretismo estético entre un estilo versallesco y art noveau encapsulado en este contexto caribeño, se encuentra rodeado por una verja de hierro y un inhóspito jardín definiendo, así, las lindes entre el exterior, una Habana desastrada, famélica y disfuncional, aunque luminosa, y un interior barroco, atemporal y voluptuoso, siempre nocturno.

Cruzar el umbral en un proceso ritual, según van Gennep, implica incorporarse a un mundo nuevo (37), un mundo donde se suspenden las normas y vivencias previas del que lo franquea. Así lo proclama la hermana de Eri, cuando, antes de su primera visita a la casa y ante las reticencias de Gaia de acompañarla, la tienta con las siguientes palabras: «pero no [sabes] quién puedes llegar a ser» (14) en clara alusión a la capacidad catártica que comportará la experiencia. Cada cruce del umbral de esta casa fuera del espacio y del tiempo, supondrá para la joven la experiencia de diversos ritos iniciáticos, todos de carácter fuertemente sexual, en los que su yo presente se irá desdibujando, desorientando en los pasillos, salas y recovecos de una casa laberíntica -incluso Gaia se referirá al lugar como «una Creta en La Habana» (137) - que, en cada una de las visitas e incluso durante las mismas, parece variar de forma y aspecto:

Bajo sus pies, el suelo mutaba, ora emergiendo como un farallón, ora hundiéndose como un pantano. Gaia se resignó a lo irremediable: allí era imposible ingerir algo que no tuviera un efecto devastador. Tal vez fuera el destino de quien se adentraba en aquel averno: alucinar sin tregua, confundir el rumbo, perder para siempre la certeza de lo que es verdadero... y todo ello, con la angustia de quien desea escapar y no puede. La idea de estar muerta se alojó en su ánimo consecuentemente (93). 
Significativamente, y como le advierte su acompañante y guía durante su primera incursión, el tiempo interno de la construcción y el externo no transcurren de idéntico modo ya que, en este particular espacio, se detiene: "cuando salgas de aquí, allá afuera no habrá transcurrido ni un instante» (77). Así, tras sus diversos pasos por el lugar, Gaia siempre se encontrará desubicada y desorientada sobre el lapso cumplido en él.

Lo interesante en el proceso ritual que sobrelleva Gaia es su ambigua voluntad de participación. Nos encontramos constantemente a la protagonista vacilando sobre sus desconcertantes experiencias y demostrando una resistencia contumaz a volverlas a repetir, resistencia que siempre vencerá su curiosidad o la tentación de reencontrarse con su enigmático amante. Gaia es una novicia -como así se la denomina en varias ocasiones durante el relato- aparentemente contra su voluntad, es una elegida que debe exorcizar sus demonios represivos tanto en sus circunstancias personales como sociales: debe liberar su sexualidad entumecida y, al mismo tiempo, utilizar esta como instrumento para disociarse de un mundo exterior que amenaza su integridad de pensamiento. Pero es que, como se señalaba anteriormente, el cruce sucesivo de límenes es el que aboca a la muchacha hacia un camino sin retorno; cada paso, cada transición, la distancia de una realidad indeseable.

En este sentido, las tribulaciones de Gaia en la casa asemejan a las fases de los ritos de iniciación de cultos mistéricos como los de Isis o Eleusis que se mencionan explícitamente en la narrativa. Lo que es más sugestivo, la protagonista llegará a vincularlos con el domicilio donde acontecen los sucesos: "Centros iniciáticos de múltiples significados. ¿Cuál sería el de la casa? Quizá sus pasajes enmarañados sirvieran de protección. [...] Pero los laberintos tenían otra función: preparaban el alma en la iniciación de los misterios» (137). El suceder de tránsitos de Gaia, sin embargo, desvela, muy lentamente, su significación última, puesto que los procesos mistéricos, ante todo, se fundamentan en la experiencia y no en el dogma o razonamiento; son pura pulsión, pura carne. Desde su primera irrupción orgiástica, con un despliegue sensorial y sexual espectacular y rodeada de seres misteriosos y evanescentes tan acogedores como lascivos, las sucesivas entradas en el lugar, irán convirtiéndose en rutinas más individuales, lúgubres y sórdidas, rayando en el terror más absoluto. Así, durante el primer ceremonial, Gaia participa como miembro de un trío sexual contemplado por una multitud enfervorecida (74-76), en una bacanal oficiada por Erinle, que cubrirá con su azulado semen a todos los regocijados presentes (89-92), y en una gozosa relación lésbica con Oshún (93-95). En posteriores accesos, se verá asaltada y forzada multitudinariamente por seres oscuros y repulsivos (141-145) o, en la sección más truculenta de la narración, sufrirá la acometida sexual de la grifería de una bañera como expresión última de la identificación de la propia casa como instrumento y agente del rito: «El grifo se movía acompasadamente y las manos que sujetaban sus muñecas secundaban la cadencia de su indefinible amante. La tensión comenzó a fatigarla y sus rodillas temblaban sin control, pero el baño no cedió su 
presa. Los ojillos de las paredes observaron con placer aquella nueva travesura de la casa» (181).

De esta forma, cual iniciada en el culto agrario y regenerativo de Eleusis, Gaia, que no casualmente posee un nombre que la liga con la mística de lo terrestre, recorre fases de deleite y oscuridad para, finalmente, llegar a una suerte de claridad y discernimiento sobre su presencia en la casa y la naturaleza de esta. Pero la casa resiste explicaciones fáciles, escatima y falsea pistas, se metamorfosea y cobra vida: «...pero jamás oyó hablar de [un laberinto] que cambiará de la noche a la mañana, como un espejismo de adornos mutantes. Semejante locura, se dijo, debía ser una creación del trópico. Esa capacidad de perenne disfraz era un atributo único de la mansión. Como todo lo demás en su isla» (177). Esta capacidad mutable se explicaría por la naturaleza simbólica de los ceremoniales y del lugar en el que acontecen: «Eso es la ceremonia: un acto simbólico. Después las fuerzas se pondrán en movimiento; pero ese movimiento no sirve de nada sin la voluntad. Así es que lo que hagan ustedes con esas fuerzas desatadas concierne a sus almas» (88). Y es que la casa es un pasaje, una prueba, de ambiguos objetivos, procedimientos y consecuencias. Por una parte, despliega un ambiente antitético y rebelde frente a la cruda realidad socioeconómica de la isla, pero su finalidad no es prender la llama revolucionaria, desafiar el poder dictatorial, sino, todo lo contrario, sublimar las restricciones y padecimientos en un sometimiento satisfecho, erótico y estoico ante las limitaciones externas ${ }^{4}$. Es precisamente la rebeldía de Gaia, su negativa a plegarse a los postulados revolucionarios en la universidad, y, por consiguiente, el riesgo de ser señalada, excluida o encarcelada, lo que incitará a los orishas protectores a forzarla a atravesar los umbrales de la mansión mutante para doblegar su espíritu disconforme. Pero si todo ritual, todo paso de encrucijadas clásico, parece evolucionar en un proceso lineal hasta alcanzar una culminación, un cambio de estado, rol o identidad, la casa de juegos de la novela de Chaviano, es esencialmente rizomática, en el sentido antifundacional y subterráneo de este concepto expuesto por Deleuze y Guattari (1980). Así, incluso aunque al fin de la narrativa Erinle parece haber conformado a Gaia sobre la inutilidad de oponerse al estado de cosas de la sociedad cubana, ella seguirá inquieta y cuestionándose sobre sus posibilidades de alcanzar un conocimiento fidedigno de su situación personal, social y ritual: "A pesar de sus continuas visitas a la mansión

4. Los artículos críticos de Anna Chover (2006) y Maribel San Juan (2006) sobre la obra se concentran en esta vertiente erótica como sublimación resignada del autoritarismo político en la isla y señalan cómo lo que ocurre en la casa, el sometimiento sexual de Gaia con el fin de aplacar su voluntad y anular sus aspiraciones sediciosas, son un remedo sadomasoquista de lo que acontece en el exterior de la vivienda a nivel sociopolítico. En este sentido, la casa se interpretaría como una reproducción metonímica en miniatura de la isla y sus circunstancias. Si bien concordamos en gran medida con estas interpretaciones, insistimos en que la gran ambigüedad del texto no conlleva lecturas definitivas ni cerradas. 
seguía en el mismo estado de ignorancia que al inicio de su periplo, y sospechó que nunca averiguaría mucho aunque acosara con sus preguntas a sus moradores» (191).

«Durante el periodo liminal, intermedio, las características del sujeto ritual (el pasajero) son ambiguas, ya que atraviesa un entorno cultural que tiene pocos, o ninguno de los atributos del estado pasado o venidero y en la tercera fase (reagregación o reincorporación) se consuma el paso", con estas palabras, Victor Turner (101-102), signa el destino del sujeto ritual en transformación en el umbral. No obstante, como veíamos en Casa de juegos, Gaia no logrará incorporarse plenamente a un nuevo nivel social, espiritual o de conciencia. Lo mismo ocurrirá en Nuestra parte de noche, con su exposición de lo ritual liminar como un progreso continuado e inconcluso a través de las décadas, controlado y oficiado por la oscura saga familiar de los Bradford. En términos de representación ritual, física y simbólica, la novela de Enríquez está repleta de sugerencias, referencias y posibilidades. Desde la constante presencia de alusiones a advocaciones de figuras redentoras del imaginario popular argentino como Guachito Gil, San La Muerte o San Güesito, entre otras, hasta los ceremoniales esotéricos que orquesta la orden secreta en torno a cuyas actividades se articulan gran parte de las tramas de esta compleja narrativa. Lo notable en esta novela, como en la obra de Chaviano, es que la actividad ocultista o esotérica de los personajes se incardina en la realidad prosaica de tal manera que discurren parejas y se nos muestran como cara y reverso de la existencia y la cotidianidad.

Entre las diversas casas que pueblan el texto, dos de ellas en particular sobresaldrán por su potencial liminar: la mansión de la familia Bradford, bautizada como Puerto Reyes, en la provincia norteńa de Corrientes, fronteriza con Brasil y Paraguay, cercana a las Cataratas de Iguazú, y la casa abandonada bonaerense que Enríquez retoma del relato «La casa de Adela» (2016). La primera es una construcción en un entorno retirado, feraz y selvático, diseñada con todas las galanuras del gusto de un rico hacendado de los ańos 20 del siglo xx:

Amaba la casa de catorce habitaciones, con su piscina olímpica, las tejas, las galerías frescas y el patio central, con una fuente y orquídeas y sauces. Algunas de las ventanas tenían vitrales franceses; alrededor de la casa, Charles Blanchard había plantado quinientas especies de plantas y había abierto senderos que era obligatorio mantener limpios o la selva volvía, feroz, a cubrirlo todo (113).

La segunda reproduce el tópico de la casa de barrio abandonada y destartalada, pero misteriosa y sugerente, de las narrativas clásicas de terror:

La casa no es especial a primera vista, pero si desde arriba se pudiera bajar y quedar flotando frente a ella, aparecerían los detalles. [...] La casa a veces parece sonreír. Los dos ojos cerrados, las ventanas tapiadas con ladrillos, le dan un aspecto antropomórfico [...]. Tuvo la impresión de que se miraban, de que sus ventanas tapiadas eran dos ojos cuadrados que le decían te estuve engañando, cuando pasaste todos esos años por mi 
vereda me hice la tonta, me escondí, pero ahora quiero que sepas, quiero que cuentes que tengo algo adentro (213).

Ambas, pese a sus diferencias, comparten una naturaleza paradójicamente periférica, marginal, demostrando ser, al mismo tiempo, lugares de poder, portales hacia territorios del más allá: «Una noche [Juan] me habló de puertas que podía abrir y de casas que, por fuera, tenían un aspecto, pero, por adentro, eran completamente distintas» (406). Pero la apertura de dicho pasaje no es automática, solo puede ser favorecida por la facultad clarividente de Juan y Gaspar, padre e hijo, dotados del don de la mediumnidad. Por ello, ambos, como otros previamente desde los orígenes ingleses de la Orden a mediados del XVIII, son codiciados por los dirigentes de dicho colectivo en su búsqueda de los arcanos alquímicos de la inmortalidad. A nivel ritual, la novela nos presenta la celebración periódica de un ceremonial en la mansión Bradford, que convoca a miembros e iniciados y que, mediante la transfiguración del médium en un ente de atributos diabólicos, abre un canal de comunicación con la Oscuridad. Esta, al tiempo que se cobra su tributo en forma de marcas sangrientas, mutilaciones y muertes entre los asistentes, revela enigmas que los oficiantes deben desentrañar para conseguir sus ansías de saber trascendente. Pero el implacable uso y abuso que la Orden ejerce sobre sus médiums, incluso aunque estos se hallen, como Juan y Gaspar, emparentados con la cúpula de la misma, llevará a Juan a explorar estos espacios por cuenta propia y a intentar alejar a su vástago de las garras de su despiadada familia.

Así, en Nuestra parte de noche el rito de paso que implican sus ceremoniales se asocia con el poder malévolo de la sombra que parece exigir dolor y sangre a cambio de conocimiento. Este proceso se hace siniestramente patente en la figura de los invunches, niños robados o comprados, espantosamente deformados, y que, siguiendo el imaginario mapuche, actuarían como cancerberos de las guaridas de magos y brujos. Sin embargo, en la narrativa, se nos muestra cómo Mercedes, una de las líderes de la Orden y abuela de Gaspar, colecciona a estos seres degradados, aviesamente maltratados, sin ningún tipo de justificación para el propio ritual: "Ahora el primer chico estaba en una jaula oxidada y sucia que posiblemente había cargado animales. La pierna izquierda la tenía atada a la espalda en una posición que había obligado a quebrarle la cadera. Como era muy chico (¡un año?, difícil saberlo por la mugre), seguramente la quebradura había resultado sencilla» (157).

De esta manera, la actividad esotérica de los líderes del culto se traduce en la degradación de seres desvalidos, en el aplastamiento de los más débiles, en la explotación brutal de los mediadores mágicos. Y, sin embargo, y a pesar de ello, la capacidad sobrenatural que poseen estos médiums liminares de abrir espacios y de trasponer umbrales fantásticos posibilita que Juan y, posteriormente Gaspar, burlen hasta cierto punto los designios fatídicos del cónclave de la secta Bradford. La novela concluye, precisamente, con una astuta maniobra por la que Gaspar propicia que todos los dirigentes de la Orden queden atrapados y condenados más allá 
del umbral, «una boca mugrienta» (662). Paradójicamente, de este modo, las dos casas mencionadas, aunque revestidas de atributos sombríos, conjurarán a través de sus espacios crepusculares, quizá antesala del averno o el averno mismo, el propio horror que engendran. Y es que, de nuevo, como en Casa de juegos, no estamos ante un umbral ritual convencional, las propias casas son el umbral, y ese espacio que se despliega dentro de ellas, «el Otro Lugar» (665) se dibuja como un quicio eterno, que abre una localización espectral, atemporal, silenciosa pero repleta de signos de muerte y donde se intuye la existencia de extraños e invisibles pobladores:

Cuando el pantano quedaba atrás, Gaspar se daba vuelta a ver el paisaje. Era hermoso aunque descolorido, probablemente por la falta de luz. Terminaba en un campo abierto, no muy grande y vacío, la soledad de un páramo en un mundo hueco. Ahí, en el páramo, les dejaban cosas a ellos, los visitantes. [...] Regalos. [...]. En la primera excursión se dieron cuenta de que estaban hechos de hueso (659).

Los que en él penetran y permanecen no se elevan o varían de estado, sino que, como víctimas propiciatorias, se adentran en lo que pareciese una muerte segura, pasando a formar parte inerte y perpetua de la Oscuridad, que las necesita para nutrirse y persistir. Sin embargo, como en la narrativa de Chaviano, no hallamos una resolución cerrada tampoco en este ejemplo y la incertidumbre deja abiertos canales inexplorados como ya señalamos en otro trabajo (Díez Cobo 150-153). La vieja casa bonaerense abandonada a la que aludíamos, uno de los portales más significativos de la narrativa, y la que engulle a la pequeña Adela, prima y compañera de juegos del Gaspar niño, permanecerá también como un enigma. La indagación curiosa que el grupo de cuatro amigos desarrollan en el interior de la casa, que los atrae con un persistente zumbido cual arácnido hambriento, se convierte en un lugar de horrores donde las dimensiones exteriores no se corresponden con las interiores -que se expanden y tornan laberínticas- y donde los pequeños exploradores, contemplan la presencia de restos humanos -dientes, uñas, párpados-, perciben luminosidades, sonidos y paisajes imposibles y, donde, finalmente, tras una puerta que resiste cualquier forcejeo, desaparece, aparentemente por voluntad propia y para siempre, Adela (337-347). Cabe señalar que Adela, hija de una miembro de la Orden, es una nińa marcada por la Oscuridad, que le cercenó un brazo, durante uno de los ceremoniales. De alguna forma, la joven se halla pues especialmente conectada con este espacio insólito desde el principio y, por lo tanto, su naturaleza es ya liminar.

El trauma de haber arrastrado, de algún modo, a Adela al otro lado obsesionará, durante años, a Gaspar, y a los otros visitantes, Vicky y Pablo, y el recuerdo de lo acontecido los acosará acusadoramente. $Y$, sin embargo, la novela se cierra de forma irresuelta, con un Gaspar, ya adulto, llamando a Adela desde el otro lado del umbral, especulando sobre su posible supervivencia, tantos años, en tal inhospitalario lugar: «En esa tierra él podía entrar y salir y buscar. En esa tierra él era bienvenido. Si ella seguía ahí, podía encontrarla. ¿Sería una niña todavía? ¿Qué le habían dado de 
comer? ¿El lugar había sido una boca para ella? Tenía que estar seguro. Del otro lado, el tiempo era otra cosa. Podía buscarla» (666-667).

Afirmaba Turner que los atributos de la liminaridad son necesariamente ambiguos y difíciles de clasificar; esta incapacidad de situar inequívocamente a lo liminar y a sus seres, como estamos comprobando en el análisis de estas dos novelas, se hace extensible también a los espacios transicionales donde acontece el rito de paso. Ninguna de las construcciones comparadas nos aporta respuestas unidireccionales y suscitan más perplejidades que certezas. En un sentido similar, además de muchos de los aspectos señalados, si algo llama la atención en las dos narrativas es un entrecruzamiento de referencias constantes y ambiguas a la sexualidad, el dolor y la muerte. Ambos relatos se mueven entre los dos aparentes extremos de una forma constante y fluida. El Eros y el Thánatos fluctúan siguiendo un trazado anti-dualista. En Casa de juegos, las prácticas sexuales polimorfas que encuentra Gaia en la residencia están acompañadas por su constante titubeo entre el apetito de experimentarlas y el rechazo al acatamiento silenciador que implican. Como bien expresa la protagonista: «Dolor y caricias, suavidad y espinas: de eso estaba hecho el placer» (75). En Nuestra parte de noche la actividad bisexual compulsiva de Juan, como manifestación de su naturaleza de "andrógino mágico» (85), acompañada de las múltiples descripciones de prácticas sádicas dentro de los ceremoniales rituales de la orden nos remiten a un universo donde, como en Casa de juegos, el placer y el dolor son experiencias de tránsito ritual, a menudo intercambiables, con fronteras difuminadas 5 . Simbólicamente, si nos remitimos al origen del título de la novela de Enríquez, encontramos que esta lo tomó del primer verso del poema 113 de la poeta Emily Dickinson, "Our share of night to bear» (13), que nos habla de la transición entre la noche y el día, la dualidad oscuridad-claridad, y el emerger dificultoso, que no todos logran, desde las sombras a la luz.

\section{Casas de tiempo: la historia y sus reversos}

Un fenómeno de la contemporaneidad es la espacialización capitalista, la generalización de casas «sin raíces», «un agujero geométrico» vertical, donde se han suprimido estancias tradicionales como el sótano, y situadas en edificios que se alinean en pasajes geométricamente trazados por donde circulan los seres humanos en masa, como lo harían por tubos indiferenciados (Luquín 192). Este retrato choca con el de casas que siguen un modelo arquitectónico clásico, premoderno, aisladas, concebidas con una individualidad inconfundible, y estructuradas en varios niveles, en una

5. Van Gennep se refiere al rol de la sexualidad y/o el dolor en los ritos de paso insistiendo en la función del coito como coadyuvante mágico (58) y en el recurso a las vejaciones y mutilaciones como procesos de diferenciación individual y colectiva (111), todas cuestiones que se hacen patentes en las siniestras solemnidades que acontecen en ambas narrativas. 
completitud emuladora de lo antropomórfico. Y este segundo modelo constructivo es el que siguen todos los edificios significativos que protagonizan las dos novelas estudiadas y, en gran medida, gran parte de las casas encantadas que pueblan la literaturas fantásticas y góticas. Además, como sustento a la hora de conformar estas construcciones como espacios plenos, hay un elemento que emerge indiscutible: la historia.

En las dos narrativas, se aborda la relación entre las dimensiones históricas y fantásticas de similar modo; nos hallamos en ambos casos ante dos cronotopos yuxtapuestos, pero con puentes que los enlazan. Curiosamente, en los dos textos, dichos puentes solo pueden ser cruzados o debe ser facilitado su paso por mediación de seres mágicos, liminares, los orishas en Casa de juegos y los médiums en Nuestra parte de noche. En principio pueden parecer mundos escindidos, con dinámicas espaciales y temporales muy divergentes entre sí: la voluptuosidad y el exceso de la casa de juegos frente al empobrecido escenario de la realidad cubana fuera de ella en la novela de Chaviano, y el mundo de quietud y tenebrosidad del «Otro Lugar» frente a la cotidianeidad del otro lado del umbral en la de Enríquez. Sin embargo, la conclusión que alcanzamos al final de los dos textos es que ambos espacios, ambos tiempos son, a la postre, cara y envés de la misma moneda, de la misma entidad; el uno sin el otro no pueden subsistir, no pueden ser interpretados. En Casa de juegos los orishas alternan su vida dentro y fuera de la casa, interaccionan con los seres humanos, comparten atributos de humanidad y, pese a habitar una atmósfera embriagadora de puertas adentro, no ignoran los padecimientos al otro lado de sus muros e intervienen sobre estos como así confirma Erinle a Gaia: «Mi grupo tiene colaboradores en los consejos donde se decide la suerte de los estudiantes. Hemos logrado evitar la expulsión de algunos, avisándoles de manera indirecta, pero contigo no funcionó» (162). En Nuestra parte de noche, de la misma manera, el espacio oscuro que se extiende allende las puertas que despejan los médiums, aunque lo pareciese, no es un territorio lúgubre aparte, ya que el mundo "externo" y las tribulaciones de sus habitantes, tal como vemos en la novela, no son vitalistas u optimistas, conforman un continuo con el anterior. Ese espacio insondable no deja, así, de ser una proyección invertida, oscura, del mundo real. Existen elementos paisajísticos reconocibles en él y sus espectrales habitantes son los restos de los que una vez vivieron del lado luminoso y vivo de la frontera:

Gaspar no quería detenerse a ver pero lo hizo: del otro lado del vidrio sucio se veía la luna sobre los árboles, muchos árboles, un bosque quieto, como si la casa estuviese en una colina, en un lugar más alto que permitiese ver ese paisaje, ese panorama. El bosque no le pareció lindo. También podía ser una pintura muy detallada, pensó. Una pintura de una ventana que daba a un bosque. Era eso. Igual la pintura tenía algo desagradable, parecía una trampa. Toda la casa era una trampa (345). 
La mirada abismada de Gaspar resulta muy significativa: este inframundo, que desconocemos si cuenta con un dios primordial -a imagen del clásico Érebo-, o entidad volitiva que lo rija, sí se trasluce como un ser o lugar primitivo e instintivo, instigado por saciar sus instintos. Los dos espacios convergentes de la novela muestran que el reinado de las sombras permea a todo y todos, haciendo caso omiso al trazado artificial de lindes. Y, de nuevo, la tensión ambigua entre Eros y Thánatos se hace patente.

Por otra parte, más allá de esta relación ontológica entre marcos narrativos, las dos obras explicitan contextos perfectamente identificables historiográficamente. Chaviano nos transmite múltiples pistas sobre la situación política, social y económica en el entorno en que se desenvuelve Gaia: represión ideológica, carencia y cortes de suministros, delaciones en el ámbito universitario, entre otras cuestiones. La vida "pública» de Gaia se retrata como llena de limitaciones espirituales y logísticas: «Ya se disponía a entrar en la ducha cuando se acordó de que no había agua. Volvió a vestirse y fue al patio para sacar un cubo del tanque destinado a las emergencias» (104). Además, en conversación con los orishas, estos la instan a no nadar contracorriente en una sociedad que no deja opción a ello; solo es posible decantarse por un estoicismo gozoso. En este escenario, la casa se convierte en un microcosmos invertido de la realidad exterior, un universo aparte pero que se nutre de las necesidades libidinales de los externos y que, por ello, contribuye a conformar una realidad con páginas diversas pero solapadas: «Bajo un disfraz engañosamente verosímil debían existir múltiples mundos superimpuestos en capas, como túneles subterráneos que permanecen invisibles para quienes deambulan por la superficie. El mundo era apariencia» (188).

La conexión histórica en Nuestra parte de noche es multifactorial. Los orígenes de la familia Bradford ilustran diversos eventos de la historia mundial y, más concretamente argentina, desde el siglo XVIII hasta mediados del xx. Además, varios personajes constituyen emblemas de hechos históricos reseñables. Este es el caso del padre de la niña Adela, opositor y desaparecido durante la dictadura militar, o Luis, tío de Gaspar, quien, ante el riesgo de ser represaliado por su disidencia, debió exiliarse en Brasil. Asimismo, las posibilidades clarividentes de Juan le permiten captar los lamentos y espíritus de los aplastados genocidamente por los militares en un año de represión tan crítico como 1978:

La ciudad gritaba, el aire estaba lleno de ruegos y rezos y risas y aullidos y sirenas y la vibración de la electricidad y chapoteos [...]. Volvió a la casa por la noche, cuando los ruegos y los alaridos y los disparos se hicieron insoportables, cuando lo rodeaban ecos de los asesinados con los ojos vendados, los pies atados, algunos con la cara o el cuerpo hinchados, otros que se arrastraban encerrados en bolsas de arpillera, una legión que no conseguía hacer desaparecer (89). 
Dentro de los distintos capítulos de la novela, uno de ellos, «El pozo de Zañartú» (485-516) se enfoca desde una perspectiva periodística y documenta el proceso de la recuperación de cuerpos de los asesinados durante la mencionada dictadura apuntando, por lo tanto, a los crímenes cometidos durante esta: «Lo que Lynch ni Pérez Rossi mencionan, y yo tampoco, porque a veces cuesta nombrar el horror es que la guerrilla del EL tenía veintidós miembros en la selva. Y que, si ya han desenterrado más de treinta cadáveres de la fosa, quiere decir que el ejército la usaba como cementerio de todas sus operaciones clandestinas en la frontera» (489-490).

Durante el último capítulo, el correspondiente a la juventud de Gaspar, ya en los años 90, como telón de fondo, vemos a través de la vida de este joven y de su cuadrilla de amigos, situaciones y dilemas propios de la época: las crisis económicas y las consiguientes movilizaciones estudiantiles en el país, el ambiente cultural activo y comprometido, la expansión y afección del VIH entre el colectivo gay, etc. Las tramas, los personajes, son proyección pues de la historia contemporánea del país. En cuanto a las dos casas de la narrativa de Enríquez, a su vez, fungen como baluartes que entroncan con la historia argentina. Puerto Fuertes es la representación de un mundo de terratenientes, compenetrados con la clase dirigente y las cúpulas militares. Sobre la casa decrépita en Buenos Aires, «la casa de Adela», poblada antaño por modestos emigrantes del este de Europa, planea la insinuación de haber podido ser un centro de detención clandestino -aspecto que juega con la intertextualidad respecto del relato original- donde, ante la desaparición de Adela, la voz narradora vaticinaba sobre el estado de la niña con un resonante y simbólico: «Nunca la encontraron. Ni viva ni muerta» (78).

¿Cómo interpretar, en última instancia, este trenzado tan trabado entre realidad y ficción en ambas narrativas? Si bien es cierto que este ejercicio de incorporación de la historia a través de lo ficcional no es nuevo y en las literaturas de corte posmoderno ha sido acotado con denominaciones como «historia apócrifa», acuñada por Brian McHale, (1987) y «metaficción historiográfica» por Linda Hutcheon (1988), esta particular conjunción entre historiografía y narrativas de lo fantástico no ha sido abordada con igual amplitud y repercusión crítica. En lo observado en las narrativas de Chaviano y Enríquez, como ya se ha mencionado, las caras fantástica e histórica del relato se presentan como parte de un mismo flujo espacio-tiempo, conformando una tercera dimensión, en la línea que Michel Foucault describió sus heterotopías y que, en su tercer principio, nos evoca una similitud muy palpable con la plasmación de lo historiográfico a través de los mimbres de lo fantástico: «La heterotopía tiene el poder de yuxtaponer en un único lugar real distintos espacios, varias ubicaciones que se excluyen entre sí» (437-438). Muy sugerente es también la interpretación, como en el caso de las utopías, de estos contra-espacios como paradójicos reflejos en el espejo: «el espejo funciona como una heterotopía en el sentido en que hace que este sitio que ocupo en el momento en que me miro en el cristal sea a la vez absolutamente real, en relación con todo el espacio que lo rodea, y absolutamente 
irreal, puesto que está obligado, para ser percibido, a pasar por ese punto virtual que está allá lejos» (435).

Siguiendo la formulación del filósofo francés, estos particulares espacios, arrinconados dentro de las dinámicas sociales por su naturaleza heterodoxa y anticanónica, se mueven al paso de tiempos también marcados por la particularidad: las heterocronías (438). A espacios divergentes, corresponderán pues temporalidades de idénticas características. Es decir, y a sabiendas de que la propuesta de Foucault excede con mucho el marco que se ha trabajado en el presente análisis, podemos interpretar esta particular encarnación en espacios heterodoxos -casas liminares o umbrales- de hechos históricos embebidos por seres, circunstancias y espacialidades fantásticas como una suerte de revulsivo contra las lecturas uniformes y acotadas de la memoria de los hechos humanos. Retomando nuevamente la perspectiva ritual con la que comenzamos, y siguiendo los postulados de Victor Turner (171): si partimos de que la liminaridad se entiende en el rito como un tiempo y lugar de alejamiento de las normas asumidas en una sociedad, puede entenderse a su vez como un periodo de revisión profunda de los axiomas y valores principales del marco socio-cultural en que tiene lugar. Así, estos textos, a través de distintos procedimientos rituales, propondrían una relectura revisionista y subversiva de parte de las historias nacionales de Cuba y Argentina desde los márgenes, desde las fronteras materiales y figuradas de sus construcciones encantadas.

\section{Conclusiones}

Resulta fascinante localizar narrativas que, si bien relativamente distantes en cronología y origen, sin embargo, presentan un número tan elevado de concomitancias como sucede en el caso de las novelas que aquí se han considerado. Ambas explotan las posibilidades del género fantástico en su vertiente terrorífica y gótica para explorar los resquicios intersticiales que se abren entre la realidad y los mundos insólitos y siniestros. Focalizando su eje crítico en torno al tópico de la casa encantada como arquitectura invertida de los espacios realistas, pero, al mismo tiempo, profundamente anclada en dichos espacios como reflejo siniestramente paródico y distorsionado, Casa de juegos y Nuestra parte de noche logran crear atmósferas perturbadoras donde las fronteras entre discursos de distinta entidad se confunden y ensamblan. La naturaleza limítrofe de las casas protagonistas y su apertura a otras dimensiones alternativas infunden un rico diálogo sobre la naturaleza misma de los seres inverosímiles, monstruos en cuanto que conjunciones aparentemente imposibles de rasgos y esencias. Más concretamente, si algo hemos subrayado en este estudio, es el recurso a un proceso tan inspirador como el ritual que afianza esta conexión con lo efímero y transitorio, con lo mutable y paradójico para, desde ese tránsito, constituir un firme abordaje de una amplia serie de posibilidades críticas. Entre estas últimas, hemos destacado aquí la relacionada con el juego discursivo 
que en ambos textos permite incorporar hechos históricos al flujo revisionista e irreverente de la ficción fantástica. En definitiva, este examen, desde una perspectiva comparada, ha buscado poner de relieve que aunque muchas líneas divisorias en textos como los seleccionados se nos pueden antojar como sólidas e infranqueables resultan ser, por el contrario, particularmente porosas.

\section{Referencias bibliográficas}

Botting, Fred, y Edwards, Justin D. «Theorising Globalgothic». Glennis Byron (ed.). Globalgothic. Manchester: Manchester University Press, 2013: 11-24.

Carroll, Noël. The philosophy of horror: or, paradoxes of the heart. Nueva York \& Londres: Routledge, 2004.

Casanova-Vizcaíno, Sandra, y Ordiz, Inés (eds.). Latin American Gothic in Literature and Culture. Londres: Routledge, 2017. https://doi.org/10.4324/9781315307671

Casas, Ana. «Prólogo». Ana Casas y David Roas (eds.). Las mil caras del monstruo. León: Eolas, 2018: 7-18.

Castro, Andrea. «El motivo del umbral y el espacio liminal». José Miguel Sardiñas (ed.). Teorías hispanoamericanas de la literatura fantástica. La Habana: Casa de las Américas, 2007: 255-262.

Chaviano, Daína. Casa de juegos. Barcelona: Planeta, 1999.

Chaviano, Daína. "Serie. La Habana Oculta». Daina Chaviano Author. Sitio web oficial. 2008-2021. https://www.dainachaviano.com/serie.php?item=1\#.YBKom3mCHIV. Consultado el 28 Ene 2021.

Chover Lafarga, Anna. "Algolagnia. Notas sobre el masoquismo y la mujer en la novela Casa de juegos de Daína Chaviano». Dolores Fernández López y Fernando RodríguezGallego (coords.). Campus stellae: haciendo camino en la investigación literaria. Santiago de Compostela: Universidad de Santiago de Compostela, 2006: 393-401.

Deleuze, Gilles y Guattari, Félix. "Introducción: Rizoma». Mil mesetas (Capitalismo y esquizofrenia). Valencia: Pre-textos, 2002, 9-32.

Dickinson, Emily. «Our share of night to bear». The complete poems of Emily Dickison. Summit: Start Publishing, 2012, 13.

Díez Сово, Rosa María. «Arquitecturas del hogar invertido: reescribiendo la casa encantada». Brumal: Revista de Investigación sobre lo Fantástico, 8:1, (2020): 135-156. https:// doi.org/10.5565/rev/brumal.633

Douglas, Mary. Purity and danger: an analysis of concepts of pollution and taboo. Londres: Routledge, 2002.

Enríquez, Mariana, «La casa de Adela». Las cosas que perdimos en el fuego. Barcelona: Anagrama, 2016: 65-80.

Enríquez, Mariana. Los peligros de fumar en la cama. Barcelona: Anagrama, 2017.

EnRíQuez, Mariana. Nuestra parte de noche. Barcelona: Anagrama, 2019.

Foucault, Michel. «Espacios diferentes». Estética, Ética y Hermenéutica: obras esenciales, vol. III. Barcelona: Paidós, 1999, 430-441.

GarcíA, Patricia. Space and the posmodern fantastic in contemporary literature: the architectural void. Nueva York: Routledge, 2015. https://doi.org/10.4324/9781315740829 
Hutcheon, Linda. A poetics of Postmodernism: history, theory, fiction. Nueva York: Routledge, 1988.

Luquín Calvo, Andrea. Remedios Varo: el espacio y el exilio. Alicante: Universidad de Alicante, 2009.

McHale, Brian. Posmodernist fiction. Nueva York: Routledge, 1987.

Neumann, Iver B. "Introduction to the forum on liminality». Review on International Studies, 38, (2012): 473-479. https://doi.org/10.1017/S0260210511000817

Roas, David, Tras los limites de lo real. Una definición de lo fantástico. Madrid: Páginas de Espuma, 2011.

SAN JuAN, Maribel. "Eros en una isla maldita: alegoría, poder y sexualidad en Casa de juegos de Daína Chaviano». Mester, 35:1, (2006): 22-35. https://doi.org/10.5070/ M3351014640

Turner, Víctor W. El proceso ritual. Estructura y antiestructura. Madrid: Taurus, 1988.

van Gennep, Arnold. Los ritos de paso. Madrid: Alianza, 2008. 